\title{
Urethral Closure Pressure at Stress: A Predictive Measure for the Diagnosis and Severity of Urinary Incontinence in Women
}

\author{
Anne-Cécile Pizzoferrato ${ }^{1,2}$, Arnaud Fauconnier ${ }^{1,2}$, Xavier Fritel ${ }^{3}$, Georges Bader ${ }^{1}$, Philippe Dompeyre ${ }^{1}$ \\ ${ }^{1}$ Department of Gynaecology and Obstetrics, Intercommunal Hospital Center of Poissy-Saint-Germain-en-Laye, Poissy, France \\ ${ }^{2}$ Research unit EA7285, Risk and Safety in Clinical Medicine for Women and Perinatal Health, Versailles St-Quentin University, Montigny-le-Bretonneux, \\ France \\ ${ }^{3}$ Poitiers University, INSERM CIC1402, University Hospital of Poitiers, Poitiers, France
}

\begin{abstract}
Purpose: Maintaining urinary continence at stress requires a competent urethral sphincter and good suburethral support. Sphincter competence is estimated by measuring the maximal urethral closure pressure at rest. We aimed to study the value of a new urodynamic measure, the urethral closure pressure at stress (s-UCP), in the diagnosis and severity of female stress urinary incontinence (SUI).

Methods: A total of 400 women without neurological disorders were included in this observational study. SUI was diagnosed using the International Continence Society definition, and severity was assessed using a validated French questionnaire, the Mesure du Handicap Urinaire. The perineal examination consisted of rating the strength of the levator ani muscle (0-5) and an assessment of bladder neck mobility using point $\mathrm{Aa}(\mathrm{cm})$. The urodynamic parameters were maximal urethral closure pressure at rest, s-UCP, Valsalva leak point pressure $\left(\mathrm{cm} \mathrm{H}_{2} \mathrm{O}\right)$, and pressure transmission ratio (\%).

Results: Of the women, 358 (89.5\%) were diagnosed with SUI. The risk of SUI significantly increased as s-UCP decreased (odds ratio [OR], $0.92 ; 95 \%$ confidence interval, $0.88-0.98$ ). The discriminative value of the measure was good for the diagnosis of SUI (area under curve > 0.80). s-UCP values less than or equal to $20 \mathrm{~cm} \mathrm{H}_{2} \mathrm{O}$ had a sensitivity of $73.1 \%$ and a specificity of $93.0 \%$ for predicting SUI. The association between s-UCP and SUI severity was also significant.

Conclusions: s-UCP is the most discriminative measure that has been identified for the diagnosis of SUI. It is strongly inversely correlated with the severity of SUI. It appears to be a specific SUI biomarker reflecting both urethral sphincter competence and urethral support.
\end{abstract}

Keywords: Urinary Incontinence, Stress; Bladder Neck Descent; Urethral Pressure; Urodynamics

- Research Ethics: Ethical Review Board approval was given by the Comité déthique de la recherche en obstétrique et gynécologie (CEROG 201GYN-09-01).

- Conflict of Interest: No potential conflict of interest relevant to this article was reported.

\section{INTRODUCTION}

Since the early 20th century, various authors have attempted to explain the pathophysiology of stress urinary incontinence (SUI). Enhorning hypothesized that SUI is the due to poor transmission of intra-abdominal pressure to the bladder and the part of the proximal urethra above the pelvic floor [1]. Later, McGuire et al. [2] introduced the concept of sphincteric incompetence. Today, the most accepted theory is the theory developed by DeLancey [3], which assumes that all periurethral 
and pericervical structures contribute to continence.

No research team has yet been able to measure reliably the transmission pressures in the urethra during straining. The transmission ratio measurement, which was proposed for the specific urodynamic diagnosis of SUI, was abandoned because it is influenced by many parameters and is not well correlated with the degree of SUI [4-6].

The lack of a specific SUI biomarker could be the explanation for the poor predictive value of urodynamics and the ongoing debate on whether urodynamic testing before surgery has benefits $[7,8]$. When considering evidence from these recent studies, we should reconsider the urodynamic measurements that are routinely used: are they closely correlated with the diagnosis of SUI and its pathophysiological mechanisms?

Searching for a specific SUI biomarker, our team developed a technique for measuring the urethral closure pressure at stress (s-UCP). Our objective was to evaluate the performance of the s-UCP for the diagnosis and the assessment of female SUI severity.

\section{MATERIALS AND METHODS}

\section{Population and Data Collection}

All patients without neurological conditions who underwent a urodynamic examination between April 2010 and October 2011 were included in this prospective observational study.

SUI was defined as "the complaint of involuntary leakage on effort or exertion" [9]. The severity of SUI was assessed by the International Consultation on Incontinence Questionnaire Short Form [10] and the validated French validated questionnaire, the Mesure du Handicap Urinaire (MHU) [11]. It is a graded scale, completed by the physician, including 7 subscales (urgency severity, urge urinary incontinence, day-time and night-time frequency, SUI, and hesitancy). For the SUI subscore, the severity is considered to be inversely proportional to the intensity of the stress required to induce leakage, according to the Stamey Urinary Incontinence scale [12]. It ranges from 0 (no problem) to 4 (maximal score).

Cervicourethral mobility was assessed by measuring point Aa according to the pelvic organ prolapse quantification classification [13]. The strength of the levator ani muscle was rated from 0 to 5 [14].

Urethral pressure measurements were carried out with patients in a $45^{\circ}$ upright position with a bladder volume of approximately $200 \mathrm{~mL}$. We used a CH8 double-lumen, 4 urethral eyes catheter (Porgès AH24F8, Sarlat La Caneda, France) to avoid variation in the maximum urethral closure pressure related to the sensor orientation. It was perfused with a constant filling rate $(2 \mathrm{~mL} / \mathrm{min})$ with saline solution [15]. Just before connecting catheters and beginning the measurements, the apparatus was zeroed with the atmospheric pressure at the pubic symphysis.

The maximum urethral closure pressure at rest (r-MUCP) corresponds to the difference between maximal urethral pressure during a static urethral profile and bladder pressure $(\mathrm{cm}$ $\mathrm{H}_{2} \mathrm{O}$ ). Three successive measurements were conducted with a rate of catheter removal of $1 \mathrm{~mm} / \mathrm{sec}$. The smallest value was used as the reference for the analyses.

For s-UCP measurements, the operator maintained the urethral catheter manually during coughing in the urethral sphincter area determined during the urethral profile obtained at rest. This was performed by maintaining the nearest graduation at the same distance visually from the urethral meatus during the entire cough. The intensity of coughing was guided by the doctor to be associated with the lowest-intensity leak under ordinary conditions. s-UCP corresponds to the residual pressure during a cough $\left(\mathrm{cm} \mathrm{H}_{2} \mathrm{O}\right)$ (Fig. $\left.1 \mathrm{~A}\right)$. Measures were included in the analysis if they were greater than $70 \%$ of the r-MUCP value. The average value of the r-MUCP immediately before and after the cough peak was used (Duet, Medtronic Inc., Minneapolis, MN, USA). Three similar curves were obtained and the smallest calculated value of s-UCP was used for the analysis.

$s$-UCP was calculated from the difference between urethral pressure at stress (s-UP) and bladder pressure at stress (s-BP): $\mathrm{s}-\mathrm{UCP}=\mathrm{s}-\mathrm{UP}-\mathrm{s}-\mathrm{BP}\left(\mathrm{cm} \mathrm{H}_{2} \mathrm{O}\right)$.

The pressure transmission ratio (PTR) is the increment in urethral pressure (peak of urethral pressure; PUP; $\mathrm{cm} \mathrm{H}_{2} \mathrm{O}$ ) at stress as a percentage of the simultaneously recorded bladder pressure (peak of bladder pressure; $\mathrm{PBP} ; \mathrm{cm} \mathrm{H}_{2} \mathrm{O}$ ): $\mathrm{PTR}=\mathrm{PUP} /$ PBP (Fig. 1A).

After removal of the urethral catheter, several Valsalva leak point pressure (VLPP) determinations were obtained, with the patients in the same position with a fixed-balloon rectal catheter. The lowest pressure at which leaking occurred at the external urethral meatus was chosen as the VLPP $\left(\mathrm{cm} \mathrm{H}_{2} \mathrm{O}\right)$.

\section{Statistical Analysis}

The correlations between s-UCP and other clinical and urodynamic parameters were evaluated using the Pearson correlation coefficient (r). The correlation was considered to be very strong 

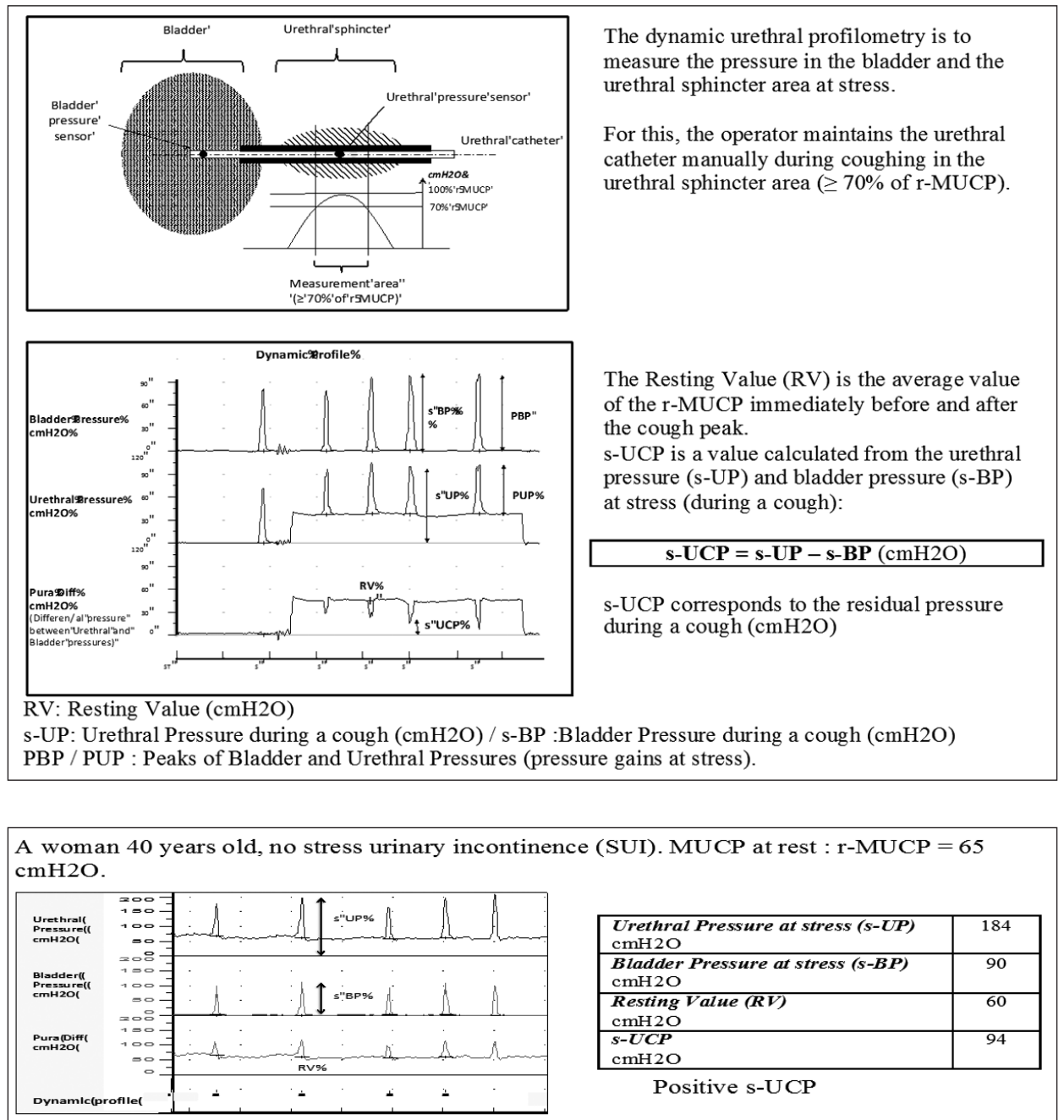

\begin{tabular}{|l|c|}
\hline $\begin{array}{l}\text { Urethral Pressure at stress }(\boldsymbol{s}-\boldsymbol{U P}) \\
\text { cmH2O }\end{array}$ & 184 \\
\hline $\begin{array}{l}\text { Bladder Pressure at stress }(\boldsymbol{s}-\boldsymbol{B P}) \\
\text { cmH2O }\end{array}$ & 90 \\
\hline $\begin{array}{l}\text { Resting Value (RV) } \\
\text { cmH2O }\end{array}$ & 60 \\
\hline $\begin{array}{l}\boldsymbol{s}-\boldsymbol{C} \boldsymbol{C P} \\
\text { cmH2O }\end{array}$ & 94 \\
\hline
\end{tabular}

Positive s-UCP

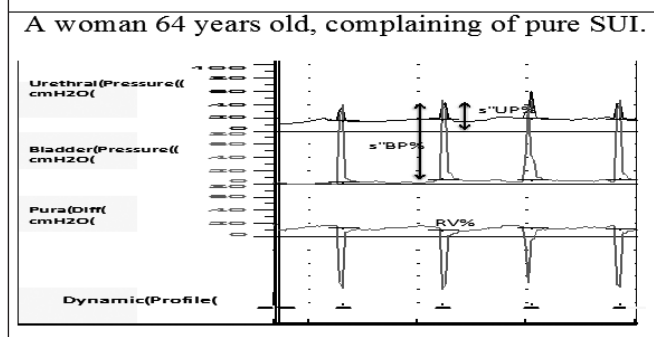

MUCP at rest : $\mathrm{r}-\mathrm{MUCP}=25 \mathrm{cmH} 2 \mathrm{O}$.

A woman 42 years old, complainig of pure SUI. MUCP at rest : $r-M U C P=37 \mathrm{cmH} 2 \mathrm{O}$.

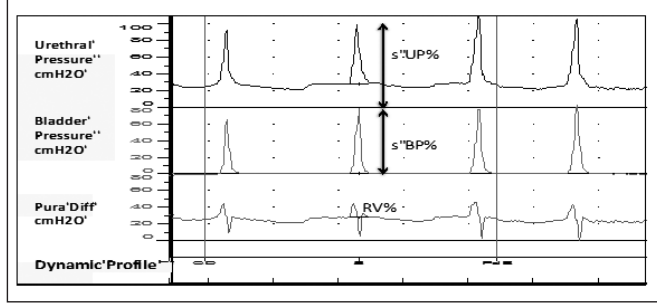

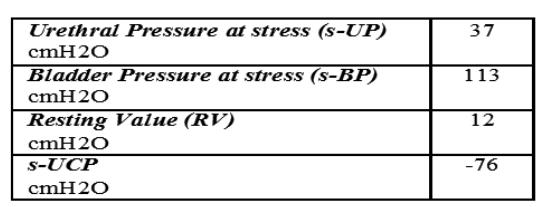

Negative s-UCP

Fig. 1. (A) Method for measuring the urethral closure pressure at stress (s-UCP). (B) Examples of curves. r-MUCP, maximum urethral closure pressure at rest (measured pressure). 
when $\mathrm{r}$ was $>0.80$, strong when it ranged between 0.50 and 0.80 , moderate when it was between 0.20 and 0.50 , and low when it was $<0.2$.

Five groups of patients defined according to their MHU score (from 0 , indicating no SUI, to 4 , indicating "urinary leakage occurring with minimal-stress activities or at all times") were compared for the different predictive variables. Analysis of variance was used to compare the means of the different parameters according to the MHU score.

The variables of point Aa and perineal testing were considered as ordinal quantitative variables, while r-MUCP, s-UCP, and PTR were analysed as continuous variables. The VLPP was recoded as follows: equal to $120 \mathrm{~cm} \mathrm{H}_{2} \mathrm{O}$ (greater than all values of abdominal pressures identified in our study) if no urinary leakage was present. When urinary leakage was present, the abdominal pressure value was noted $\left(\mathrm{cm} \mathrm{H}_{2} \mathrm{O}\right)$.

The predictive value for SUI of each of these parameters was assessed using logistic regression to examine the risk of SUI (an MHU score of 0 versus all other scores), and ordinal logistic regression to examine the severity of SUI according to the MHU scale.

Each of the parameters was studied at first separately, and then all variables considered for the prediction of SUI and severity of SUI were introduced into the models. Age and body mass index (BMI), which were considered to be potential confounders, were systematically introduced into the models.
A graphical comparison of the receiver operating characteristic (ROC) curves for the different parameters was also used to determine the best predictor of SUI diagnosis. An area under the ROC curve (AUC) between 0.90 and 1 was considered to indicate excellent discrimination, between 0.80 and 0.90 good discrimination, between 0.70 and 0.80 low discrimination, and $<0.70$ low to poor discrimination.

Analyses were conducted using Stata 9.0 (Stata Corp., College Station, TX, USA).

\section{RESULTS}

A total of 400 patients were included. Their mean age was $52.4 \pm 12.9$ years, their mean BMI was $25.3 \pm 4.6 \mathrm{~kg} / \mathrm{m}^{2}$, and their mean parity was $2.1 \pm 1.3$.

The indications for urodynamic analysis were urinary incontinence (346 women, 90.1\%), increased daytime frequency (12 women, $3.1 \%$ ), an exam before pelvic surgery (11 women, $2.9 \%$ ), urgency (8 women, $2.1 \%$ ), and recurrent urinary tract infections ( 7 women, $1.8 \%$ ).

Of the 400 patients, 358 (89.5\%) were diagnosed with SUI after symptom assessment. Of them, 218 (54.5\%) had a negative VLPP.

s-UCP

The s-UCP values ranged from $-69 \mathrm{~cm} \mathrm{H}_{2} \mathrm{O}$ to $128 \mathrm{~cm} \mathrm{H}_{2} \mathrm{O}$ (Fig.

Table 1. Patient characteristics and clinical parameters according to the MHU scale

\begin{tabular}{|c|c|c|c|c|c|c|}
\hline \multirow{2}{*}{ Characteristic } & \multicolumn{5}{|c|}{ MHU score } & \multirow{2}{*}{ P-value } \\
\hline & 0 & 1 & 2 & 3 & 4 & \\
\hline No. of patients & $42(10.5)$ & $8(2.0)$ & $133(33.2)$ & $187(46.8)$ & $30(7.5)$ & \\
\hline Age (yr) & $45.1 \pm 14.9$ & $40.2 \pm 12.1$ & $51.1 \pm 11.4$ & $53.8 \pm 11.6$ & $63.3 \pm 15.4$ & $<0.0001$ \\
\hline Parity & $1.3 \pm 0.9$ & $1.9 \pm 1.2$ & $2.3 \pm 1.3$ & $2.2 \pm 1.2$ & $2.1 \pm 1.6$ & 0.03 \\
\hline $\operatorname{BMI}\left(\mathrm{kg} / \mathrm{m}^{2}\right)$ & $24.1 \pm 3.9$ & $21.8 \pm 2.8$ & $24.3 \pm 4.1$ & $26.0 \pm 4.4$ & $28.1 \pm 6.8$ & 0.07 \\
\hline Aa point $(\mathrm{cm})$ & $-2.2 \pm 0.8$ & $-1.3 \pm 0.7$ & $-1.3 \pm 0.8$ & $-1.1 \pm 0.8$ & $-1.7 \pm 0.9$ & 0.0001 \\
\hline Perineal testing & $3.2 \pm 1.4$ & $3.1 \pm 1.5$ & $2.8 \pm 1.4$ & $2.6 \pm 1.3$ & $2.4 \pm 1.4$ & 0.01 \\
\hline Pressure transmission ratio (\%) & $76.8 \pm 18.3$ & $61.4 \pm 17.9$ & $65.6 \pm 14.7$ & $65.2 \pm 13.7$ & $72.7 \pm 17.9$ & 0.004 \\
\hline r-MUCP $\left(\mathrm{cm} \mathrm{H}_{2} \mathrm{O}\right)$ & $74.4 \pm 30.5$ & $72.9 \pm 19.7$ & $54.1 \pm 18.9$ & $46.3 \pm 18.6$ & $26.3 \pm 9.4$ & $<0.0001$ \\
\hline $\mathrm{s}-\mathrm{UCP}\left(\mathrm{cm} \mathrm{H}_{2} \mathrm{O}\right)$ & $52.4 \pm 29.9$ & $27.4 \pm 41.1$ & $16.7 \pm 20.1$ & $6.8 \pm 18.9$ & $1.3 \pm 19.7$ & $<0.0001$ \\
\hline VAS (out of 10) & $0 \pm 0$ & $4.9 \pm 1.0$ & $5.5 \pm 1.9$ & $6.2 \pm 1.9$ & $7.9 \pm 1.6$ & $<0.0001$ \\
\hline ICIQ-SF (out of 21) & $5.9 \pm 6.5$ & $8.0 \pm 1.7$ & $9.5 \pm 2.7$ & $11.3 \pm 2.6$ & $14.7 \pm 2.0$ & $<0.0001$ \\
\hline
\end{tabular}

Values are presented as number (\%) or mean \pm standard deviation.

MHU, Mesure du Handicap Urinaire; BMI, body mass index; r-MUCP, maximum urethral closure pressure at rest; s-UCP, urethral closure pressure at stress; VAS, visual analogue scale; ICIQ-SF, International Consultation on Incontinence Questionnaire-Short Form. 
$1 \mathrm{~B}$ shows different types of curves). The mean s-UCP was $52.3 \pm 29.9 \mathrm{~cm} \mathrm{H}_{2} \mathrm{O}$ in continent women and $10.5 \pm 20.9 \mathrm{~cm} \mathrm{H}_{2} \mathrm{O}$ in stress incontinent patients, and it significantly decreased with the MHU score (Table 1). The mean s-UCP decreased significantly with age $(\mathrm{P}<0.05)$. Significant differences were not associated with parity or BMI, but a decreasing trend was observed.

A strong correlation was found between s-UCP and r-MUCP $(\mathrm{r}=0.62)$, and moderate correlations with PTR $(\mathrm{r}=0.48)$ and point $\mathrm{Aa}(\mathrm{r}=-0.31)$.

A strong inverse correlation was found between s-UCP and the MHU score $(r=-0.53)$. The correlations between the MHU score and the other parameters were poor to moderate.

\section{Prediction of SUI}

In the multivariate analysis, associations (also adjusted for age and $\mathrm{BMI}$ ) were significant for s-UCP, perineal testing, and point Aa (odds ratio [OR], 0.92 [95\% confidence interval $\{\mathrm{CI}\}$, 0.88-0.98]; 0.67 [0.47-0.95]; 3.32 [1.85-5.96]).

The ROC analysis showed excellent discrimination for sUCP (AUC $=0.90)$, good discrimination for point Aa and PTR $(A U C=0.84$ and 0.80 ), and low discrimination for r-MUCP, VLPP, and perineal testing $(\mathrm{AUC}=0.79,0.76$, and 0.74 , respectively). s-UCP values less than or equal to $20 \mathrm{~cm} \mathrm{H}_{2} \mathrm{O}$ had a sensitivity of $73.1 \%$ and a specificity of $93.0 \%$. The positive likelihood ratio was 10.21 and the negative likelihood ratio was 0.29 (Fig. 2).

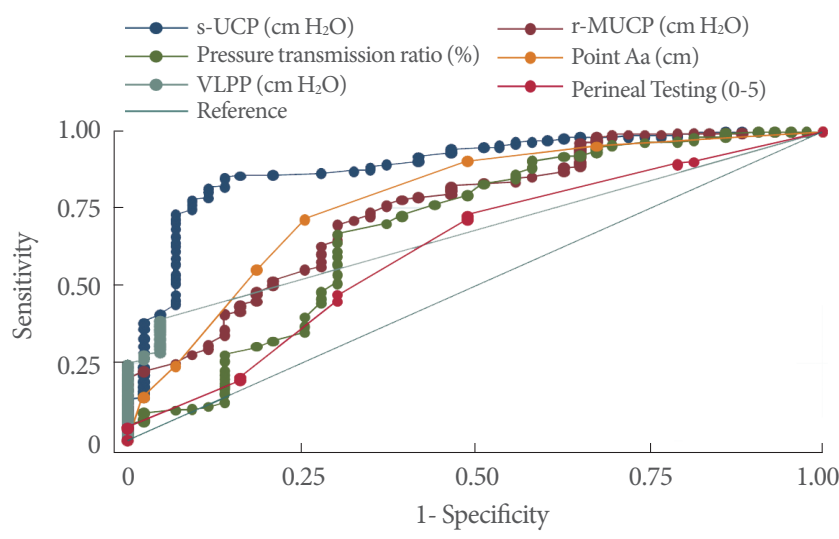

Fig. 2. Receiver operating characteristic curves indicative of the degree to which SUI was predicted by each clinical and urodynamic parameter. SUI, stress urinary incontinence; s-UCP, urethral closure pressure at stress (calculated measure); r-MUCP: maximum urethral closure pressure at rest (measured pressure); VLPP, Valsalva leak point pressure.

\section{Severity of SUI}

The multivariate analysis showed significant associations between the severity of SUI and s-UCP, VLPP, and levator ani muscle strength. Those variables were inversely associated with more severe SUI (OR, 0.96 [95\% CI, 0.94-0.98]; 0.99 [0.980.998]; and 0.78 [0.66-0.93], respectively). r-MUCP, point Aa and PTR were not significantly associated with the severity of SUI (OR, 1.00 [95\% CI, 0.98-1.02]; 1.26 [0.99-1.60]; and 1.01 [0.99-1.04], respectively).

\section{DISCUSSION}

\section{Main Findings}

s-UCP was found to be the most discriminative measure for the diagnosis of SUI. It decreased significantly with the severity of SUI and age.

\section{Limitations and Strengths}

The principal limitation of our study is the number of continent patients (with an MHU score of 0). Of the 400 women who underwent a urodynamic study (after the exclusion of pelvic organ prolapse or urinary incontinence surgery), we were only able to find 42 women who were fully continent (10.5\% of our population). It is quite difficult to recruit women without SUI in this kind of study design. Using a severity scale partially overcomes this deficiency by validating a kind of dose-response relationship.

To assess the severity of SUI in women, we used the French MHU score. Unfortunately, it has never been correlated with the pad test, but it is widely used by French physicians after being recommended by the National Agency for Accreditation and Evaluation in Health [16]. This limits the degree to which our findings can be compared to those of international studies, but it is, to our knowledge, the only validated questionnaire dealing with the circumstances of leaking without involving the notion of frequency.

The main problem in measuring the s-UCP is that it requires the examiner to have some experience: he or she must ensure that the urethral catheter is not moving in the urethra when the patient is coughing. Ideally the stress urethral pressure measures should be made at the point of highest pressure along the functional length of the urethra, but that is not technically feasible. This is the reason why we considered the measure valid for the s-UCP calculation when the resting value was more than $70 \%$ of the r-MUCP. Another validation criterion was the 
visual aspect of the curve: the measurement was considered successful for the purposes of the analysis if we observed 3 similar curves with a stable value of r-MUCP before and after coughing. If r-MUCP decreased (urethral fatigability), the appearance of the curve visually changed. We are currently working on a quantitative validation criterion for the curves.

\section{Interpretation}

Currently, there is no reliable urodynamic measurement used in the diagnosis and severity of SUI. The VLPP, which is presented as a simple and reproducible measure, has been widely disseminated among clinicians since 1993 [17]. However, it is still not standardized. The Société Interdisciplinaire Francophone d’UroDynamique et de Pelvi Périnéologie only proposed measuring the VLPP in a semisitting position, with a filling volume of $200 \mathrm{~mL}$ and an intrarectal catheter. Three successive measurements must be performed with direct visualization of the urine leakage [18]. This measure of VLPP is not always possible because some patients are not able to reproduce on the examination table sufficient valsalva manoeuvres to cause loss of urine. Thus, in our study, only 139 stress incontinent patients (38.9\%) had a positive VLPP. In the study by Haab et al. [19], the assessment of continence with VLPP was only possible in $70 \%$ of patients (intensity of abdominal pressure higher or equal to $60 \mathrm{~cm} \mathrm{H}_{2} \mathrm{O}$ ).

Because r-MUCP assesses urethral strength, it cannot be used for diagnosing SUI due to the significant overlap between continent and stress incontinent women [20], and the measure appears to be moderately correlated with the severity of SUI. Theofrastous et al. found, in a prospective study with 75 stress incontinent women (pure SUI), a moderate correlation between $r$-MUCP and the number of incontinence episodes per week (Pearson correlation coefficient $r=0.258, P=0.04$ ). There was no significant correlation between $r-M U C P$ and the pad test $(r=0.116)$ or the quality of life scale [21]. Similarly, Nager et al. [22] studied the correlations among r-MUCP, VLPP, and the severity of UI in 52 women with pure SUI $(n=46)$ or mixed urinary incontinence with predominant SUI $(n=6)$. They found a low correlation between $\mathrm{r}$-MUCP and the pad test $(\mathrm{r}<0.09)$, and moderate correlations with the Q-tip test $(\mathrm{r}=$ $0.67)$ and the quality of life score ( $r=0.10$ for $r-M U C P)$.

In our opinion, $\mathrm{s}-\mathrm{UCP}$ appears to be the most discriminative measure for use in diagnosing SUI and assessing its severity because it takes into account both the quality of the urethral sphincter and urethral mobility. With a high positive likelihood ratio and a negative likelihood ratio close to 0 , it appears to be a specific SUI biomarker that could help encourage a re-emergence of interest in urodynamic examinations, especially before anti-incontinence surgery.

To confirm the usefulness of this measure, a study with an internationally validated questionnaire in a larger population and a study about the reliability of the measure must be conducted to validate the feasibility of this measurement. Finally, a study of the impact of the s-UCP on the results of SUI surgery will be needed to confirm its clinical importance.

In conclusion, s-UCP appears to be the most discriminative measure yet identified for the diagnosis of SUI and is closely correlated with the severity of SUI. s-UCP is a global and specific urodynamic parameter that takes into account the different pathophysiological mechanisms of SUI: the quality of the urethra, its sphincter, and periurethral structures.

\section{REFERENCES}

1. Enhorning G. Simultaneous recording of intravesical and intraurethral pressure. A study on urethral closure in normal and stress incontinent women. Acta Chir Scand Suppl 1961;Suppl 276:1-68.

2. McGuire EJ, Lytton B, Pepe V, Kohorn EI. Stress urinary incontinence. Obstet Gynecol 1976;47:255-64.

3. DeLancey JO. Structural support of the urethra as it relates to stress urinary incontinence: the hammock hypothesis. Am J Obstet Gynecol 1994;170:1713-20.

4. Constantinou CE. Urethrometry: considerations of static, dynamic, and stability characteristics of the female urethra. Neurourol Urodyn 1988;7:521-39.

5. Richardson DA, Ramahi A. Reproducibility of pressure transmission ratios in stress incontinent women. Neurourol Urodyn 1993; 12:123-30.

6. Meyer S, de Grandi P, Caccia G, Gerber S. Pressure transmission ratio: is it a reliable parameter in increased urethro-vesical junction mobility? Neurourol Urodyn 1997;16:277-84.

7. Nager CW, Brubaker L, Litman HJ, Zyczynski HM, Varner RE, Amundsen C, et al. A randomized trial of urodynamic testing before stress-incontinence surgery. N Engl J Med 2012;366:1987-97.

8. van Leijsen SA, Kluivers KB, Mol BW, Broekhuis SR, Milani AL, Bongers MY, et al. Can preoperative urodynamic investigation be omitted in women with stress urinary incontinence? A non-inferiority randomized controlled trial. Neurourol Urodyn 2012;31: 1118-23.

9. Abrams P, Andersson KE, Birder L, Brubaker L, Cardozo L, Chap- 
ple C, et al. Fourth International Consultation on Incontinence Recommendations of the International Scientific Committee: Evaluation and treatment of urinary incontinence, pelvic organ prolapse, and fecal incontinence. Neurourol Urodyn 2010;29:213-40.

10. Avery K, Donovan J, Peters TJ, Shaw C, Gotoh M, Abrams P. ICIQ: a brief and robust measure for evaluating the symptoms and impact of urinary incontinence. Neurourol Urodyn 2004;23:322-30.

11. Amarenco G, Kerdraon J, Perrigot M. Echelle dévaluation du handicap pelvien: mesure du handicap urinaire (MHU). In: Pelissier J, Costa P, Lopez S, Mares P. Rééducation vésico-sphinctérienne et ano-rectale. Paris: Masson; 2007. p. 498-504.

12. Stamey TA. Endoscopic suspension of the vesical neck for urinary incontinence in females. Report on 203 consecutive patients. Ann Surg. 1980;192:465-71.

13. Bump RC, Mattiasson A, Bø K, Brubaker LP, DeLancey JO, Klarskov $\mathrm{P}$, et al. The standardization of terminology of female pelvic organ prolapse and pelvic floor dysfunction. Am J Obstet Gynecol 1996;175:10-7.

14. Laycock J. Clinical evaluation of the pelvic floor. In: Schüssler B. Pelvic floor re-education: principles and practice. London: Springer-Verlag; 1994. p. 42-8.

15. Brown M, Wickham JE. The urethral pressure profile. Br J Urol 1969;41:211-7.

16. Agence Nationale d'Accréditation et d'Evaluation en Santé. Bilans et techniques de rééducation périnéo-sphinctérienne pour le traitement de lincontinence urinaire chez la femme à lexclusion des affections neurologiques. Paris: ANAES; 2000.

17. McGuire EJ, Fitzpatrick CC, Wan J, Bloom D, Sanvordenker J, Ritchey M, et al. Clinical assessment of urethral sphincter function. J Urol 1993;150(5 Pt 1):1452-4.

18. Haab F, Amarenco G. Méthodologie de réalisation du VLPP. Lisboa: Société Internationale Francophone d'Urodynamique (SIFUD); 1998.

19. Haab F, Ciofu C, Pedron P, Lukacs B, Doublet JD, Gattegno B, et al. Feasibility of "Valsalva Leak Point Pressure". Prospective study. Prog Urol 1997;7:611-4.

20. McGuire EJ. Urodynamic evaluation of stress incontinence. Urol Clin North Am 1995;22:551-5.

21. Theofrastous JP, Bump RC, Elser DM, Wyman JF, McClish DK. Correlation of urodynamic measures of urethral resistance with clinical measures of incontinence severity in women with pure genuine stress incontinence. The Continence Program for Women Research Group. Am J Obstet Gynecol 1995;173:407-12.

22. Nager CW, Schulz JA, Stanton SL, Monga A. Correlation of urethral closure pressure, leak-point pressure and incontinence severity measures. Int Urogynecol J Pelvic Floor Dysfunct 2001;12:395400 . 